\title{
Efficacy of preoxygenation using tidal volume and deep breathing techniques with and without prior maximal exhalation
}

\author{
[Efficacité de la préoxygénation utilisant les techniques de respiration en volume \\ courant et de respiration profonde avec et sans expiration maximale préalable]
}

Usharani Nimmagadda MD, ${ }^{*} \dagger$ M. Ramez Salem MD, ${ }^{*} \dagger$ Ninos J. Joseph BSc, ${ }^{*}$ Istvan Miko MD*

Purpose: We evaluated the influence of prior maximal exhalation on preoxygenation in 15 adult volunteers using tidal volume breathing (TVB) for five minutes and deep breathing (DB) for two minutes with and without prior maximal exhalation.

Methods: Inspired and end-tidal oxygen, nitrogen and carbon dioxide were monitored continuously and recorded during room air breathing and at $30-\mathrm{sec}$ intervals during $100 \%$ oxygen TVB or DB (rate of 8 breaths $\cdot \mathrm{min}^{-1}$ ).

Results: Tidal volume breathing with prior maximal exhalation resulted in an end-tidal oxygen concentration $\left(\mathrm{ETO}_{2}\right)$ slightly higher $(P=0.028)$ at 0.5 and $1.0 \mathrm{~min}$ as compared with TVB without prior maximal exhalation at the same time periods. Regardless of whether TVB was preceded by maximal exhalation or not, 2.5 min was required to reach a mean $\mathrm{ETO}_{2}$ value of $90 \%$ or higher. With DB, there were no differences in $\mathrm{ETO}_{2}$ values at any time period and $1.5 \mathrm{~min}$ was required to reach an $\mathrm{ETO}_{2}$ of $90 \%$ or greater, with or without prior maximal exhalation.

Conclusions: Maximal exhalation prior to TVB slightly steepens the initial rise in $\mathrm{ETO}_{2}$ during the first minute, but confers no real benefit if maximal preoxygenation is the goal. Maximal exhalation prior to DB has no added value in enhancing preoxygenation.

CAN J ANESTH $2007 / 54: 6 /$ pp 448-452
Objectif: Nous avons évalué l'influence d'une expiration maximale préalable sur la préoxygénation chez 15 volontaires adultes utilisant la respiration en volume courant (TVB) durant cinq minutes et la respiration profonde (DB) pendant deux minutes, avec et sans expiration maximale préalable.

Méthode: Les concentrations inspirées et expirées d'oxygène, d'azote et de dioxyde de carbone ont été mesurées continuellement et enregistrées aux $30 \mathrm{sec}$ durant la respiration à l'air ambiant durant une TVB ou une DB d'oxygène à $100 \%$ (fréquence respiratoire de $8 \cdot \mathrm{min}^{-1}$ ).

Résultats : La respiration en volume courant avec une expiration maximale préalable a permis d'obtenir une concentration d'oxygène expiré $\left(E T O_{2}\right)$ légèrement plus élevée $(P=0,028)$ à 0,5 et I,0 min comparée à une TVB sans expiration maximale préalable aux mêmes temps. Afin d'atteindre une valeur moyenne d'ETO de $90 \%$ ou plus, 2,5 minutes étaient nécessaires, avec ou sans expiration maximale préalable. Avec la $D B$, une différence dans les valeurs d'ETO ${ }_{2}$ n'a été observée à aucune période de temps, et $I, 5$ min ont été nécessaires pour atteindre une $E T O_{2}$ de $90 \%$ ou plus, avec ou sans expiration maximale préalable.

Conclusion: Une expiration maximale préalable à une TVB accentue légèrement la montée initiale d'ETO ${ }_{2}$ durant la première minute, mais n'apporte pas de bénéfice réel si la préoxygénation maximale est visée. Une expiration maximale préalable à une $D B$ n'a pas de valeur ajoutée quant à l'amélioration de la préoxygénation.

From the Departments of Anesthesiology, Advocate Illinois Masonic Medical Center; ${ }^{*}$ and the University of Illinois College of Medicine, $†$ Chicago, Illinois, USA.

Address correspondence to: Dr. Usharani Nimmagadda, Department of Anesthesiology, Advocate Illinois Masonic Medical Center, 836

W. Wellington Avenue, Chicago, IL 60657, USA. Phone: 773-296-5619; Fax: 773-296-5362; E-mail: ninos-j.joseph@advocatehealth.com Presented in part at the Annual Meeting of the American Society of Anesthesiologists, Las Vegas, NV, October 2004.

This study was supported entirely with funds from the Department of Anesthesiology, Advocate Illinois Masonic Medical Center, Chicago, IL, USA.

Accepted for publication March 1, 2007.

Revision accepted March 20, 2007.

CAN J ANESTH 54: 6 www.cja-jca.org June, 2007 
A

DMINISTRATION of oxygen before anesthetic induction and tracheal intubation (preoxygenation) is a widely accepted maneuver designed to increase oxygen reserves and thereby slow the rate of arterial oxyhemoglobin desaturation during apnea. ${ }^{1-4}$ This is particularly important when manual controlled ventilation is undesirable (as during rapid sequence induction of anesthesia) or when difficult tracheal intubation and/ or difficult ventilation are anticipated. ${ }^{4}$

Various techniques and regimens have been advocated to accomplish preoxygenation. For many years, the traditional tidal volume breathing (TVB) for three to five minutes has been commonly practiced. ${ }^{4,5}$ The period required for preoxygenation has been shortened by using deep breathing (DB), as advocated by Gold et al., ${ }^{6}$ who used four deep breaths in $30 \mathrm{sec}$ and by Baraka et al. ${ }^{7}$ who recommended eight deep breaths within $60 \mathrm{sec}$. More recently, it has been found that extending the duration of $\mathrm{DB}$ to 1.5 or two minutes with high fresh gas flow (FGF) further improves the efficacy of preoxygenation. ${ }^{8}$

A recent study has demonstrated that maximal exhalation before TVB of oxygen can enhance the efficacy of preoxygenation. ${ }^{9}$ The authors postulated that by reducing the functional residual capacity (FRC) to approximately the residual volume, prior maximal exhalation decreases the lung nitrogen content, consequently raising the alveolar oxygen concentration during subsequent preoxygenation. That study was limited to preoxygenation using TVB and not DB. The current study was designed to evaluate the effect of prior maximal exhalation on the efficacy of preoxygenation using two techniques, TVB for five minutes and DB for up to two minutes in the same group of healthy adult volunteers.

\section{Materials and methods}

After institutional Review Board approval, 15 consenting healthy ASA physical status I volunteers (eight males/seven females with a mean $( \pm$ SD $)$ age of $31.9 \pm$ $4.5 \mathrm{yr}$ and a mean weight of $70.6 \pm 18.8 \mathrm{~kg}$ ), without history of lung or cardiac disease, were studied. The volunteers were non-bearded, non-smoking, medical students and residents recruited without inducement. The preoxygenation techniques were explained to the subjects and ample time was allowed for them to become familiar with mask breathing while maintaining a tight seal.

A single anesthesia machine (model 210 Excel, Datex-Ohmeda, Madison, WI, USA) was used throughout the studies. The circle absorber system consisted of an Ohmeda GMS absorber with barium hydroxide lime, USP (Baralyme, Chemetron Medical Div., St. Louis, MO, USA) absorbent, disposable 60 -inch corrugated breathing tubes, and a $3-\mathrm{L}$ capacity natural latex breathing bag (King Systems, Noblesville, IN, USA). The reservoir bag was fully inflated using the oxygen flush and partially occluding the mask. Preoxygenation was performed using oxygen, $10 \mathrm{~L} \cdot \mathrm{min}^{-1}$, and a tight-fitting mask, with the subjects in the supine position. The following techniques were tested in each subject: l) TVB for a five-minute period without prior maximal exhalation; 2 ) TVB for a five-minute period preceded by maximal exhalation; 3) DB for a two-minute period without prior maximal exhalation; and 4) DB for a two-minute period preceded by maximal exhalation.

When prior maximal exhalation was employed, the subject was asked to exhale fully immediately prior to mask application and initiation of the first breath. During TVB, the subjects were periodically reminded to maintain a normal tidal volume and a normal respiratory rate. During $\mathrm{DB}$, the subjects were prompted to breathe as deeply as possible at $7.5-\mathrm{sec}$ intervals. The tests were performed in a randomized order using a computer-generated random assignment table. Data were collected during room air breathing (baseline) and at 0.5 -min intervals during oxygen administration. Fifteen-minute periods of room air breathing were allowed between tests.

Measured variables included fraction of inspired oxygen $\left(\mathrm{FIO}_{2}\right)$ and end-tidal oxygen concentrations $\left(\mathrm{ETO}_{2}\right)$, end-tidal nitrogen $\left(\mathrm{ETN}_{2}\right)$, end-tidal carbon dioxide $\left(\mathrm{PETCO}_{2}\right)$, respiratory rate $(\mathrm{RR})$, and tidal volume $\left(\mathrm{V}_{\mathrm{T}}\right)$. Measurements were recorded using an Ohmeda Rascal II anesthetic and respiratory gas monitor (Datex-Ohmeda, Madison, WI, USA). Sidestream respiratory gases were sampled at a rate of 240 $\mathrm{mL} \cdot \mathrm{min}^{-1}$ from a sampling port at the Y-piece of the anesthetic circuit. Calibration with known gas mixtures was carried out according to the manufacturer's specifications prior to each use.

The sample size calculation was based on the $\mathrm{ETO}_{2}$ using results of previous preoxygenation studies. Setting alpha $=0.05,80 \%$ power, difference in means of 3 , and standard deviation of 3 , a projected enrolment of 15 subjects was considered an adequate sample size for detecting a significant difference between preoxygenation with and without prior maximal exhalation.

Statistical analyses were performed using SPSS version 15.0 (SPSS, Chicago, IL USA). A two-way analyses of variance for repeated measures were used to detect differences in concentration as functions of time and technique. Where statistical significance was 


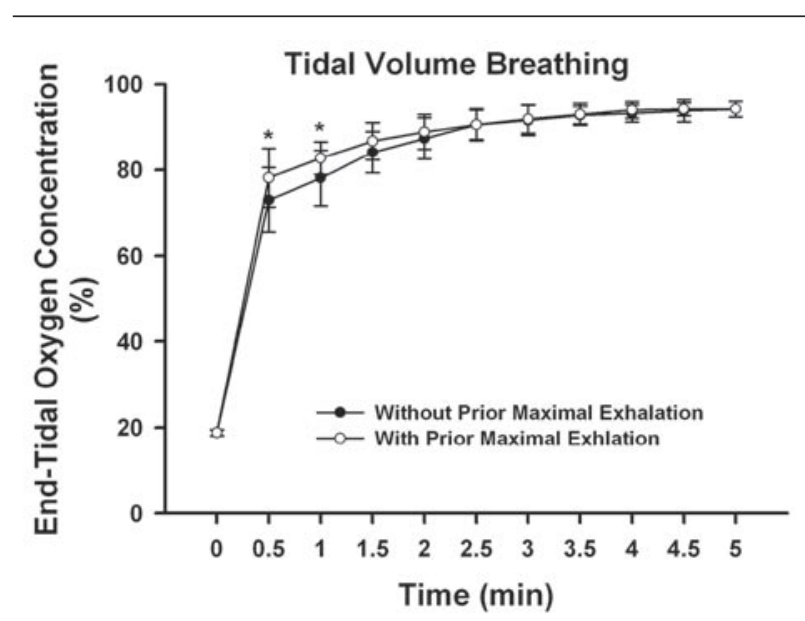

FIGURE 1 Comparison of end-tidal oxygen concentration values (mean $\pm S D$ ) over five-minute periods during simulated preoxygenation using tidal volume breathing technique after maximal exhalation $(\bigcirc)$ vs tidal volume breathing without prior maximal exhalation $(0)$. ${ }^{*}$ Denotes statistically significant differences between techniques (tidal volume breathing with or without prior maximal exhalation) at that time period. Statistical significance accepted when $P<0.05$.

found, a Student-Newman-Keuls test was applied to identify those differences. Statistical significance was accepted when $P<0.05$. Values are reported as mean \pm SD.

\section{Results}

Tidal volume breathing

The $\mathrm{FIO}_{2}$ ranged between $0.97 \%$ and $0.99 \%$ and remained unchanged between 0.5 and five minutes of TVB, both with and without prior maximal exhalation (Table I). The $\mathrm{ETO}_{2}$ increased rapidly between 0.5 and two minutes, both with and without prior maximal exhalation (Figure 1). However, the $\mathrm{ETO}_{2}$ values at the 0.5 - and 1.0 -min measurement periods were slightly, but significantly higher when maximal exhalation preceded TVB $(P=0.028)$. Between 2.5 min and five minutes, $\mathrm{ETO}_{2}$ plateaued between $91.8 \%$ and $94.1 \%$, both with and without prior maximal exhalation. Respiratory rate ranged between 10 and 16 breaths $\mathrm{min}^{-1}$. Mean tidal volume was $396 \pm 310$ mL. Mean $\mathrm{PETCO}_{2}$ did not vary (Table I).

\section{Deep breathing}

The $\mathrm{FIO}_{2}$ ranged between $0.975 \%$ and $0.985 \%$ and remained unchanged between 0.5 and two minutes of $\mathrm{DB}$, both with and without prior maximal exhalation (Table II). End-tidal oxygen concentration rose steeply to $75.7 \pm 6.5 \%, 86.7 \pm 3.4 \%, 90.1 \pm 2.3 \%$, and $92.0 \pm 2.3 \%$ at $0.5 \mathrm{~min}, 1.0 \mathrm{~min}, 1.5 \mathrm{~min}$ and $2.0 \mathrm{~min}$, respectively without prior maximal exhalation, and to $79.5 \pm 5.5 \%, 87.0 \pm 4.6 \%, 91.0 \pm 2.4 \%$, and $92.7 \pm$ 2.2 at the same periods with prior maximal exhalation (Figure 2). The mean $\mathrm{ETO}_{2}$ values obtained with and without prior maximal exhalation were not different from each other at any time period (Figure 2 ). During $\mathrm{DB}$, mean tidal volume was $2105 \pm 561$ $\mathrm{mL}$. Mean $\mathrm{PETCO}_{2}$ decreased significantly from $40 \pm$ $3.9 \mathrm{mmHg}$ to $34.1 \pm 2.9 \mathrm{mmHg}$ at $0.5 \mathrm{~min}$ without prior maximal exhalation and $32.1 \pm 3.8 \mathrm{mmHg}$ at 0.5

TABLE I Comparison of inspired oxygen fraction $\left(\mathrm{FIO}_{2}\right)$, end-tidal nitrogen concentration $\left(\mathrm{ETN}_{2}\right)$, and end-tidal carbon dioxide partial pressure $\left(\mathrm{PETCO}_{2}\right)($ mean $\pm \mathrm{SD})$ over a five-minute period during simulated preoxygenation by tidal volume breathing after maximal exhalation $v s$ tidal volume breathing alone. †Denotes significantly different values between preoxygenation with and without prior maximal exhalation at that time period $(P<0.05)$.

\begin{tabular}{|c|c|c|c|c|c|c|}
\hline & \multicolumn{2}{|c|}{$\mathrm{FIO}_{2}(\mathrm{mmHg})$} & \multicolumn{2}{|c|}{$\mathrm{ETN}_{2}(\mathrm{mmHg})$} & \multicolumn{2}{|c|}{$\mathrm{PETCO}_{2}(\mathrm{mmHg})$} \\
\hline & $\begin{array}{l}\text { Without prior } \\
\text { maximal } \\
\text { exhalation }\end{array}$ & $\begin{array}{l}\text { With prior } \\
\text { maximal } \\
\text { exhalation }\end{array}$ & $\begin{array}{l}\text { Without prior } \\
\text { maximal } \\
\text { exhalation }\end{array}$ & $\begin{array}{l}\text { With prior } \\
\text { maximal } \\
\text { exhalation }\end{array}$ & $\begin{array}{l}\text { Without prior } \\
\text { maximal } \\
\text { exhalation }\end{array}$ & $\begin{array}{l}\text { With prior } \\
\text { maximal } \\
\text { exhalation }\end{array}$ \\
\hline $0 \min$ (baseline) & \multicolumn{2}{|c|}{$21.1 \pm 0.6$} & \multicolumn{2}{|c|}{$78.0 \pm 1.1$} & \multicolumn{2}{|c|}{$40.4 \pm 3.9$} \\
\hline $0.5 \mathrm{~min}$ & $97.1 \pm 1.9$ & $97.2 \pm 1.7$ & $25.6 \pm 6.9$ & $18.9 \pm 6.1 \dagger$ & $36.6 \pm 6.4$ & $35.5 \pm 5.0$ \\
\hline $1.0 \mathrm{~min}$ & $97.7 \pm 1.3$ & $97.4 \pm 1.5$ & $17.6 \pm 6.9$ & $13.6 \pm 2.8 \dagger$ & $37.9 \pm 5.7$ & $36.1 \pm 5.3$ \\
\hline $1.5 \mathrm{~min}$ & $98.3 \pm 1.0$ & $97.4 \pm 3.0$ & $11.2 \pm 4.7$ & $8.9 \pm 4.4$ & $38.9 \pm 6.9$ & $36.7 \pm 6.6$ \\
\hline $2.0 \mathrm{~min}$ & $98.3 \pm 1.2$ & $98.4 \pm 0.8$ & $7.7 \pm 4.7$ & $6.4 \pm 3.7$ & $39.1 \pm 6.3$ & $37.2 \pm 7.5$ \\
\hline $2.5 \mathrm{~min}$ & $98.3 \pm 1.6$ & $98.4 \pm 0.7$ & $4.9 \pm 3.6$ & $5.0 \pm 3.1$ & $39.3 \pm 6.1$ & $37.4 \pm 4.3$ \\
\hline $3.0 \mathrm{~min}$ & $98.7 \pm 0.6$ & $98.7 \pm 0.5$ & $3.5 \pm 2.8$ & $3.7 \pm 2.7$ & $39.7 \pm 5.9$ & $39.9 \pm 5.3$ \\
\hline $3.5 \mathrm{~min}$ & $98.9 \pm 4.0$ & $98.9 \pm 0.4$ & $2.8 \pm 2.8$ & $2.6 \pm 2.0$ & $39.9 \pm 4.7$ & $39.3 \pm 5.1$ \\
\hline $4.0 \mathrm{~min}$ & $98.8 \pm 0.8$ & $98.8 \pm 0.4$ & $2.0 \pm 2.0$ & $1.9 \pm 1.5$ & $39.9 \pm 5.0$ & $37.5 \pm 5.3$ \\
\hline $4.5 \mathrm{~min}$ & $98.9 \pm 0.5$ & $98.9 \pm 0.4$ & $1.2 \pm 1.0$ & $1.6 \pm 1.4$ & $40.3 \pm 4.3$ & $38.7 \pm 4.2$ \\
\hline $5.0 \mathrm{~min}$ & $98.9 \pm 0.3$ & $99.0 \pm 0.0$ & $1.3 \pm 1.8$ & $1.3 \pm 1.2$ & $40.3 \pm 5.0$ & $38.2 \pm 5.5$ \\
\hline
\end{tabular}




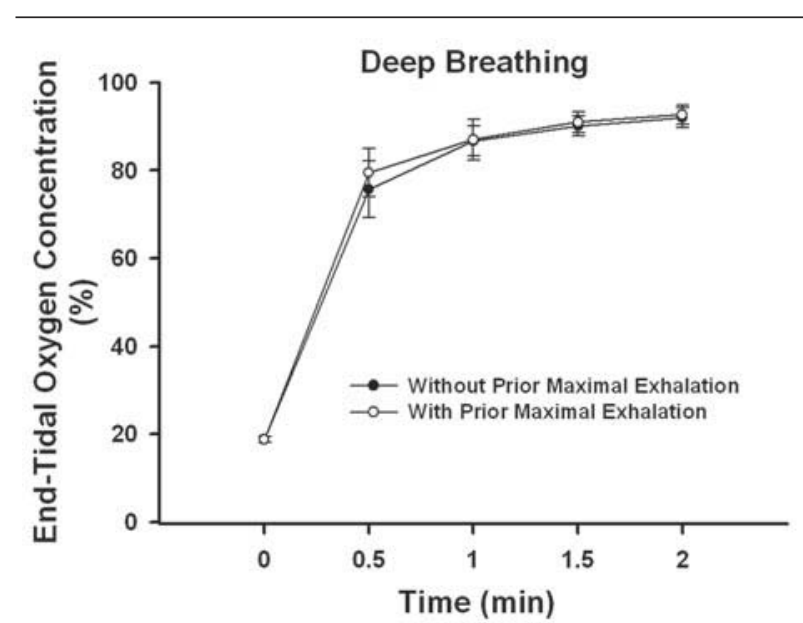

FIGURE 2 Comparison of end-tidal oxygen concentration values (mean $\pm S D$ ) over two-minute periods during simulated preoxygenation using deep breathing technique after maximal exhalation $(\bigcirc)$ vs deep breathing without prior maximal exhalation $(\bullet)$.

min when preceded by maximal exhalation (Table II). Mean $\mathrm{PETCO}_{2}$ remained constant, thereafter, with or without prior maximal exhalation.

\section{Discussion}

The present study demonstrates that prior maximal exhalation confers little or no practical benefit to preoxygenation when using either TVB or DB. Studies of preoxygenation have focused on measurements of indices reflecting its efficacy and efficiency. ${ }^{10}$ Measurements of arterial oxygen tension, ${ }^{6,7} \mathrm{ETN}_{2},{ }^{11}$ $\mathrm{ETO}_{2}{ }^{12,13}$ concentrations reflect the efficacy of preoxygenation, whereas the slowing of the rate of arte- rial oxyhemoglobin desaturation during apnea ${ }^{10,14}$ is indicative of its efficiency. Since there are many factors that affect the decrease of arterial oxyhemoglobin saturation during apnea, such as capacity of oxygen loading and total oxygen consumption, ${ }^{10,15,16}$ it is of utmost importance to maximally preoxygenate the patient to fill the alveolar and arterial compartments with oxygen, especially when difficult ventilation and/ or intubation are anticipated.

Factors affecting the efficacy of preoxygenation include $\mathrm{FIO}_{2}$, duration of breathing, and ratio of alveolar ventilation to FRC $\left(\mathrm{V}_{\mathrm{A}} / \mathrm{FRC}\right)$. Common reasons for the failure to achieve an $\mathrm{FIO}_{2}$ close to 1.0 include inadequate time for preoxygenation, ${ }^{10,12}$ a leak under the face mask, $2,5,10,17$ use of systems incapable of delivering high oxygen concentrations, ${ }^{18}$ and rebreathing of exhaled gases, such as when low FGF is used in a semiclosed circle absorber system. ${ }^{7,8}$ In the current study, the subjects were non-bearded and were familiar with the use of tight-fitting masks so as to avoid leaks between the mask and the face. In addition, the clinical endpoints indicative of a sealed system (expansion and contraction of the reservoir bag corresponding with the respiratory cycle, measurement of breath-by-breath respiratory gases, and the presence of a normal capnogram) were confirmed in all subjects. Although various anesthetic systems can be used for preoxygenation, we used the circle absorber, because it is the system most frequently used in the operating room and it has been found to be as effective as other systems specifically designed for preoxygenation. $.^{9}, 11,19$ Although increasing the FGF from 5 to $10 \mathrm{~L} \cdot \mathrm{min}^{-1}$ using the circle absorber system has little impact on the $\mathrm{FIO}_{2}$ during TVB, it may have a noticeable effect during $\mathrm{DB} .{ }^{8}$ Because of the breathing characteristics of the circle system, DB using a FGF of less than 10 $\mathrm{L} \cdot \mathrm{min}^{-1}$ may cause minute ventilation to exceed the FGF, resulting in rebreathing of exhaled gases $\left(\mathrm{N}_{2}\right)$

TABLE II Comparison of inspired oxygen fraction $\left(\mathrm{FIO}_{2}\right)$, end-tidal nitrogen concentration $\left(\mathrm{ETN}_{2}\right)$, and end-tidal carbon dioxide partial pressure $\left(\mathrm{PETCO}_{2}\right)$ concentrations (mean $\pm \mathrm{SD}$ ) over a two-minute period during simulated preoxygenation by deep breathing after maximal exhalation $v s$ deep breathing alone. ${ }^{*}$ Denotes significant difference from baseline (room air breathing) value $(P<0.05)$. †Denotes significantly different values between preoxygenation with and without prior maximal exhalation at that time period $(P<0.05)$.

\begin{tabular}{|c|c|c|c|c|c|c|}
\hline & \multicolumn{2}{|c|}{$\mathrm{FIO}_{2}(\%)$} & \multicolumn{2}{|c|}{$\mathrm{ETN}_{2}(\%)$} & \multicolumn{2}{|c|}{$\mathrm{PETCO}_{2}(\mathrm{mmHg})$} \\
\hline & $\begin{array}{l}\text { Without prior } \\
\text { maximal } \\
\text { exhalation }\end{array}$ & $\begin{array}{l}\text { With prior } \\
\text { maximal } \\
\text { exhalation }\end{array}$ & $\begin{array}{l}\text { Without prior } \\
\text { maximal } \\
\text { exhalation }\end{array}$ & $\begin{array}{l}\text { With prior } \\
\text { maximal } \\
\text { exhalation }\end{array}$ & $\begin{array}{l}\text { Without prior } \\
\text { maximal } \\
\text { exhalation }\end{array}$ & $\begin{array}{l}\text { With prior } \\
\text { maximal } \\
\text { exhalation }\end{array}$ \\
\hline 0 min (baseline) & \multicolumn{2}{|c|}{$21.1 \pm 0.6$} & \multicolumn{2}{|c|}{$78.0 \pm 1.1$} & \multicolumn{2}{|c|}{$40.4 \pm 3.9$} \\
\hline $0.5 \mathrm{~min}$ & $98.5 \pm 0.5$ & $97.5 \pm 1.8$ & $19.2 \pm 5.7$ & $15.2 \pm 5.1$ & $34.1 \pm 2.9^{*}$ & $32.1 \pm 3.8^{*} \dagger$ \\
\hline $1.0 \mathrm{~min}$ & $98.1 \pm 1.2$ & $98.1 \pm 1.3$ & $9.3 \pm 3.7$ & $8.2 \pm 4.1 \dagger$ & $35.7 \pm 3.6^{*}$ & $34.9 \pm 3.2 *+$ \\
\hline $1.5 \mathrm{~min}$ & $98.1 \pm 1.4$ & $98.1 \pm 1.4$ & $5.4 \pm 2.5$ & $4.6 \pm 2.0$ & $36.1 \pm 4.7^{*}$ & $35.1 \pm 4.7^{*}$ \\
\hline $2.0 \mathrm{~min}$ & $98.0 \pm 1.9$ & $98.5 \pm 0.8$ & $3.8 \pm 2.1$ & $3.2 \pm 2.0$ & $35.3 \pm 5.3^{*}$ & $33.9 \pm 4.2^{*}$ \\
\hline
\end{tabular}


from the reservoir bag and consequently decreasing the $\mathrm{FIO}_{2},{ }^{7,8}$ To decrease the impact of this problem, $10 \mathrm{~L} \cdot \mathrm{min}^{-1} \mathrm{FGF}$ was used in the current study. A further indication of meticulous control of the various factors affecting the efficacy of preoxygenation in our study was the maintenance of an $\mathrm{FIO}_{2}$ between $97.1 \%$ and $99 \%$ in all subjects throughout the investigation.

Tidal volume breathing after maximal exhalation resulted in a more rapid rise in $\mathrm{ETO}_{2}$ in the first minute of preoxygenation as compared with TVB without prior maximal exhalation. These results are similar to the findings of Baraka et al. ${ }^{9}$ who found that prior maximal exhalation hastened oxygenation during the first two minutes of TVB. However, it is evident from the current investigation that the time required to reach an $\mathrm{ETO}_{2}$ of $90 \%$ or higher is the same $(2.5$ min) whether maximal exhalation preceded TVB or not (Figure 1).

The current study also demonstrates that during $\mathrm{DB}$, the time-courses of preoxygenation with and without prior maximal exhalation were identical. In contrast to prior maximal exhalation preceding TVB, it is evident that the decrease in FRC resulting from maximal exhalation was minor in comparison with the level of alveolar ventilation associated with $\mathrm{DB}$, and thus, no differences were noted. Regardless of whether prior maximal exhalation is used or not, 1.5 min of $\mathrm{DB}$ are still required to reach an $\mathrm{ETO}_{2}$ of $90 \%$ or greater.

In conclusion, 1) maximal exhalation prior to preoxygenation slightly enhances the rise in $\mathrm{ETO}_{2}$ during the first minute of TVB, but provides no added benefit when used before DB; 2) to achieve maximal efficacy $\left(\mathrm{ETO}_{2} \geq 90 \%\right)$, preoxygenation should be carried out for at least $2.5 \mathrm{~min}$ with TVB or $1.5 \mathrm{~min}$ with DB in adults, regardless of whether maximal exhalation is used or not.

\section{References}

1 Dillon JB, Darsie ML. Oxygen for acute respiratory depression due to administration of thiopental sodium. J Am Med Assoc 1955; 159: 1114-6.

2 Drummond GB, Park GR. Arterial oxygen saturation before intubation of the trachea. An assessment of oxygenation techniques. Br J Anaesth 1984; 56: 987-93.

3 American Society of Anesthesiologists Task Force on Management of the Difficult Airway. Practice guidelines for management of the difficult airway: an updated report by the American Society of Anesthesiologists Task Force on Management of the Difficult Airway. Anesthesiology 2003; 98: 1269-77.

4 Anonymous. Preoxygenation: physiology and practice (Editorial). Lancet 1992; 339: 31-2.
5 Berthoud M, Read DH, Norman J: Pre-oxygenation - how long? Anaesthesia 1983; 38: 96-102.

6 Gold MI, Duarte I, Muravchick S. Arterial oxygenation in conscious patients after 5 minutes and after $30 \mathrm{sec}-$ onds of oxygen breathing. Anesth Analg 1981; 60: 313-5.

7 Baraka AS, Taha SK, Aouad MT, El-Khatib MF, Kawkabani NI. Preoxygenation: comparison of maximal breathing and tidal volume breathing techniques. Anesthesiology 1999; 91: 612-6.

8 Nimmagadda U, Chiravuri SD, Salem MR, et al. Preoxygenation with tidal volume and deep breathing techniques: the impact of duration of breathing and fresh gas flow. Anesth Analg 2001; 92: 1337-41.

9 Baraka AS, Taha SK, El-Khatib MF, Massouh FM, Jabbour DG, Alameddine MM. Oxygenation using tidal volume breathing after maximal exhalation. Anesth Analg 2003; 97: 1533-5.

10 Benumof JL. Preoxygenation: best method for both efficacy and efficiency (Editorial). Anesthesiology 1999; 91: 603-5.

11 Carmichael FJ, Cruise CJ, Crago RR, Paluck S. Preoxygenation: a study of denitrogenation. Anesth Analg 1989; 68: 406-9.

12 Berry CB, Miles PS. Preoxygenation in healthy volunteers: a graph of oxygen "washin" using end-tidal oxygraphy. Br J Anaesth 1994; 72: 116-8.

13 Bhatia PK, Bhandari SC, Tulsiani KL, Kumar $\Upsilon$. Endtidal oxygraphy and safe duration of apnoea in young adults and elderly patients. Anaesthesia 1997; 52: 175-8.

14 Gambee AM, Hertzka RE, Fisher DM. Preoxygenation techniques: comparison of three minutes and four breaths. Anesth Analg 1987; 66: 468-70.

15 Farmery AD, Roe PG. A model to describe the rate of oxyhaemoglobin desaturation during apnoea. Br J Anaesth 1996; 76: 284-91.

16 Benumof JL, Dagg R, Benumof R. Critical hemoglobin desaturation will occur before return to an unparalyzed state following $1 \mathrm{mg} / \mathrm{kg}$ intravenous succinylcholine. Anesthesiology 1997; 87: 979-82.

17 Nimmagadda U, Salem MR, Joseph NJ, et al. Efficacy of preoxygenation with tidal volume breathing. Comparison of breathing systems. Anesthesiology 2000; 93: 693-8.

18 Mertzlufft F, Zander R. Optimal pre-oxygenation: the NasOral-system. Adv Exp Med Biol 1994; 345: 45-50.

19 Hamilton WK, Eastwood DW. A study of denitrogenation with some inhalation anesthetic systems. Anesthesiology 1955; 16: 861-7. 